\title{
Aoristo)))))
}

International Journal of Phenomenology, Hermeneutics and Metaphysics

\section{OSilêncio de Heidegger'}

\author{
Heidegger's Silence
}

Luiz Alberto Thomé Speltz Filho

Professor de Filosofía do Programa de Formação em Matemática Olímpica da UIFPR ${ }^{2}$

\section{RESUMO}

Trata-se de um pequeno ensaio sobre a disposição necessária para a lida com a filosofia. 0 texto fala de Heidegger, pois foi construído para a ocasião de um seminário sobre mesmo tema, mas não invade a sua obra. De outro modo, o trabalho se propõe a pensar sobre o lugar de encontro da filosofia, o lugar em que Heidegger deixa de ser apenas nosso objeto de estudo e passa a ser um companheiro de conversa. Esse lugar é o silêncio - que, para a filosofia, é e precisa ser fala.

\section{PALAVRAS-CHAVE}

Silêncio; Heidegger; Sentido

\section{ABSTRACT}

This short essay is about the necessary disposition for dealing with philosophy. The text deals with Heidegger because it was constructed in the occasion of a seminary with the same theme, but it does not invade his work. In another way, this work aims to think the meeting place of the philosophy, the place where Heidegger stops being only our study object and starts being a dialog partner. This place is the silence, which, for philosophy, is and must be speech.

\section{KEYWORDS}

Silence; Heidegger; Meaning

Parece-me que há dois modos de apresentar um seminário sobre Heidegger: o primeiro é organizando todo o arcabouço conceitual levantado durante a leitura de uma ou mais de suas obras, cuidando para não sair da linha e não se perder na tradução; e o segundo, que me soa mais interessante, consiste na renúncia ao texto, em uma tentativa de perquirir o assunto mesmo da filosofia - e, portanto, o

\footnotetext{
${ }^{1}$ Este trabalho foi exposto em um curso ministrado pelo Alexandre Gomes Pereira, meu professor - e amigo.

2E-mail: luiz2004@hotmail.com 


\section{Aoristo)))))}

\section{International Journal of Phenomenology, Hermeneutics and Metaphysics}

assunto de todo e qualquer filósofo: o fenômeno, o aparecimento. A renúncia, assim, não é nada senão um querer se familiarizar e, essencialmente, conversar (?!) com Heidegger.

Aceitarei esse segundo modo, correndo risco de me desviar e de passar alguma vergonha.

De início, pensando no ponto mais atraente - e também mais absurdo - do nosso caminho, podemos nos perguntar: o que é preciso para que a conversa aconteça? Pode parecer fundamental, à primeira vista, que falemos a mesma língua, que estejamos diante um do outro ou pelo menos que consigamos dizer um para o outro algumas palavras ou fazer alguns gestos. Se é assim, poderia dizer que o tempo todo estou conversando com aqueles que me rodeiam, pronunciando ou não palavras, como com o porteiro do meu condomínio, quando lhe aceno, ou com o padeiro, apontando e pedindo pão, e mesmo com quem está distante, através de carta, computador, celular etc. Mas como poderia conversar com Heidegger sobre o assunto da filosofia? Neste caso, a coisa é mais complicada, não apenas por conta da língua, do idioma - pois isso talvez pudesse ser resolvido - , mas porque podemos dizer que hoje está um pouco mais difícil encontrá-lo.

Suponhamos, porém, que ele esteja aqui, diante de nós, encostado numa cadeira, com as mãos sobre a mesa, esperando-nos para uma conversa. Só isso nos basta? Que conversa estaríamos tendo ou que conversa poderíamos ter? Falaríamos sobre o que escreveu, sobre as suas obras? Assim estaríamos conversando como filósofos? O que sabemos essencialmente sobre a sua obra, para que saibamos o que dizer? Temos realmente disposição para entendê-la, lê-la ou ouvir o seu autor contála? O que mais Heidegger teria a nos dizer que já não disse?

Bom, diante dessas questões, faria então diferença tê-lo, aqui, à frente, se nós mesmos não estivéssemos afinados com o seu assunto? Não, seguramente. Neste sentido, não me parece certo que para conversar com Heidegger seja preciso apenas que ele esteja conosco - assim como me parece um erro achar que o seu texto nos tornará aptos ao encontro. O que faremos então? Como nos afundaremos no assunto que queremos, para que tenhamos o que dizer a Heidegger? O que é preciso para que nos saudemos uns aos outros em nosso encontro na ou com filosofia?

Ora, talvez eu possa responder a essa última questão. O que precisamos para o nosso encontro...? Não precisamos de nada! O assunto da filosofia é onde estamos já sempre afundados. $\mathrm{O}$ assunto da filosofia é apenas o que temos: o fenômeno, o aparecimento, e nada além disso. No entanto, como essa obviedade poderia resolver o nosso problema? Basta que falemos a respeito de qualquer coisa que já estaremos fazendo filosofia? Se eu começasse a falar, por exemplo, sobre a cadeira, a mesa etc. seria o suficiente? Seria? Mas falar o que sobre a mesa? O que tenho que falar a seu respeito? Filosofia é falar qualquer coisa sobre qualquer coisa? A mesa serve para que coloquemos papéis em cima, serve para me apoiar, serve para não sei mais o quê... A mesa tem pernas, tem isso ou aquilo... Ora, por que isso seria filosofia? Seríamos todos filósofos quando descrevemos ou divagamos sobre o que temos ao redor? O padeiro é um filósofo quando me pergunta se eu quero o pão mais 


\section{Aoristo)))))}

\section{International Journal of Phenomenology, Hermeneutics and Metaphysics}

branquinho ou mais passado? O porteiro é filósofo quando me acena e me pergunta se peguei o guarda-chuva ou quando me conta sobre a vizinhança? Todos eles, todos nós estaríamos afinados com o que Heidegger faz apenas por isso? Não me parece que seja assim... O que então seria preciso falar sobre o fenômeno para que estejamos fazendo filosofia? Aliás, o que é o fenômeno? É isso que deveríamos nos perguntar? Pois desconfio que a essa questão nem o porteiro, nem o padeiro, nem quem fosse teria por onde responder.

O que é o fenômeno? Está aí! Essa questão me matou. Por muito tempo me debrucei sobre ela. Talvez não devesse ter tido dificuldade para respondê-la, mas o caso foi outro, pois no geral não sabia nem como começar. E, por isso, tão forte me foi o impasse que mesmo nos dias em que estive envolvido em afazeres importantes do cotidiano me peguei tomado por sua força. Também aos domingos, no extraordinário da vida, dias em que me tenho reservado à missa, dedicando-me a ouvir a palavra do padre: ficava olhando ao meu redor e tentando entender o que precisava ver para saber o que é isso que vejo.

A imagem de Jesus, por exemplo, uma pintura atrás do altar, com a inscrição "sou eu o caminho, a verdade e a vida". Uma pintura simples na técnica, nada demais, e eu a estive olhando, esperando que me respondesse, que falasse comigo. Não apenas eu, na verdade, mas também todos os que a reverenciavam - inclusive o padre, que, mesmo no seu corpo vivo, falando o que falava, continuava sempre menor do que a imagem, a ponto de a homilia se mostrar baixa, sussurrante, e a figura, alta, gigante. Mas era apenas uma imagem, uma pintura, uma parede, teria ela como nos responder? Aliás, não havia quase expressão na face de Jesus, não acho que ele tenha querido me dizer algo, era simplesmente Jesus me olhando. $\mathrm{O}$ que poderia querer comigo? Ora, o que eu precisava ver naquela imagem?

Fato é que, num domingo, no meio de uma dessas indagações, o padre pediu silêncio para que pudéssemos solicitar perdão pelos erros da semana e nos colocássemos no estado de graça, deixando-nos efetivamente entrar na igreja. Sem isso, permaneceríamos fora, na sujeira da rua. Precisávamos daquela cerimônia, da pausa do padre e da cantoria, se quiséssemos ouvir o nosso coração falar e, acompanhando a voz do alto, nos purificar.

Naquele momento, mesmo ordenado a fechar os olhos, mantive-os abertos, observando a liturgia. Éramos apenas eu e o Jesus-parede de olhos abertos. Todos os outros permaneciam quietos, com a cabeça baixa, imóveis, imersos. Então, de repente, sem que o visse, meus olhos também se fecharam, iluminando o profundo do coração: eis que me dei com o seu vazio, com a sua pobreza. Um coração indigente! Um coração que era só ferida! E assim, na miséria, algo se abriu: não fora o meu coração pedindo perdão pela vida desgraçada, mas algo mais simples, um pensamento simples, crescido no vazio do peito, e que rezava mais ou menos assim: "para ouvir o coração falar, é preciso calar a boca, fechar os olhos, e deixá-lo dizer; é preciso dar lugar, pois sem o silêncio nada pode falar". Mas esse ainda não era o ponto. "Também sem o silêncio do coração, aquela pintura de Jesus não poderia ser vista, o padre não poderia orar, nada haveria. O silêncio de um sustenta o outro. Assim, justo onde há mais força de aparecimento, onde há mais voz, também ali o 


\section{Aoristo)))))}

International Journal of Phenomenology, Hermeneutics and Metaphysics

silêncio é fundamento".

E nisso, nesse ponto, atravessou-me ainda outro pensamento, mais grave, superior ao anterior: "para a voz do coração ou para a tenência da pintura, deve haver silêncio não apenas de um ou de outro, mas o meu silêncio. Ou, se se quiser de outro modo, eu precisei e preciso ser apenas silêncio".

Não que eu tivesse ou tenha de me calar ou que algo em mim precise ficar quieto para que tudo possa aparecer, como se o meu corpo ou mente precisasse parar, a fim de que o resto fosse ouvido. Não. Pois é também neste silêncio que corpo, mente ou qualquer coisa se sustenta. Em outras palavras, eu, o meu silêncio, ou, melhor, eu, o silêncio, em minha indigência, sendo indigência, nada, sou fundamento, lugar do aparecimento. Lugar não no sentido de um espaço, de um terreno, e tampouco de um vácuo que se preenche de algo, como se houvesse vazio antes do que aparece, mas aquilo que deixa o aparecimento ser aparecimento. Lugar, simplesmente, como deixar-ser.

Por isso mesmo, o silêncio também não deve ser entendido como falta de som, falta de barulho ou coisa parecida, mas como possibilidade de aparecimento enquanto o aparecimento é aparecimento. Poderíamos dizer, por exemplo, que as cores são o silêncio da (ou para a) pintura, pois, vendo-a, não as percebo. Assim, também, andando com o exemplo, a pintura atrás do altar da igreja é o silêncio de (ou para) Jesus...

Dissemos há pouco que não é preciso nada para que nos afundemos no assunto da filosofia, e agora podemos dizer mais: para o aparecimento mesmo é preciso: nada, silêncio, eu, deixar-ser. Isso é espantoso. Esteve sempre tão aí, mas onde estive para que não percebesse isso que pode ser visto como o meu atestado de óbito, meu atestado de nada? Ora, perdido em mim mesmo - mas sem saber que o estava. Antes, o meu nada tinha nome, havia sido acobertado pela ciência, sido enterrado por livros, por aulas, por toda modernidade. Agora, o nada estava revelado justamente no aberto do todo.

Olhei novamente para a figura de Jesus e assim pude ver que nela nada precisava ver, pois essencialmente o que ela guardava naquela ausência de toda expressão era muito firmemente apenas o silêncio. $O$ silêncio sobre mim mesmo, sobre a minha morte, o silêncio sobre o próprio silêncio. Essa guarda, esse guardar, portanto, não era o esconder, mas o pôr diante. Estou morto, e é na minha morte que Jesus aparece. Ele morreu por mim, e para que o visse tive também de estar morto. $\mathrm{Na}$ nossa morte nós nos encontramos - de olhos abertos. Muito abertos! Hoje, agora, sempre. E nesse sentimento, pela primeira vez me contive diante daquela imagem, sem querer vê-la como imagem, mas apenas me deixei olhar. Não estava vendo Jesus, mas a mim mesmo, eu estava lá. E esse era o problema: o meu nada sustentava tudo, dava e era lugar, e, também nisso, tudo podia se dissolver. Nunca havia conseguido ver Jesus, porque, quando o tentava fazer, atravessava-o e mergulhava na pobreza, no vazio, no oco do meu coração, afundava-me em mim mesmo, sem saber.

Neste sentido, então, o que é o fenômeno? O que é Jesus me olhando? É

Luiz Alberto Thomé Speltz Filho

Toledo, v. 4, n'1 (2021) p. 142-147 


\section{Aoristo)))))}

\section{International Journal of Phenomenology, Hermeneutics and Metaphysics}

simplesmente o aparecimento do meu nada, o meu aparecimento, a minha morte. E isso não significa que eu sou aquela imagem, que eu sou Jesus ou que eu sou esta mesa ou esta cadeira, mas que na minha morte eles são e estão sustentados - na medida em que eu mesmo estou sempre tendo de me renunciar. Aliás, esse é o meu modo próprio, o modo da renúncia.

O que é a cadeira? É o meu sentar nela, são as suas pernas, as suas partes, a sua cor? Nada disso, isso também é o atravessar, isso é renúncia, é silêncio. Pois também ela, enquanto fenômeno, me revela a mim mesmo, justo no meu errar, no trespassar - ou, polindo a falta: justo na minha decadência: no [erro de] ficar/acreditar na imanência. É preciso acentuar, porém, que o erro está por minha conta: não é só porque consigo atravessá-la que devo dizer que a cadeira é o nada em que se fundamenta, que ela também é apenas silêncio. Não. Mas posso dizer que ela, enquanto fenômeno, guarda - põe diante - justamente esse nada.

E o que não é o nada da cadeira? $\mathrm{O}$ sentido. $\mathrm{O}$ aparecimento do meu nada se dá no modo do sentido.

Quando nos perdemos no silêncio da cadeira, não somos levados para qualquer direção, mas para o seu uso, para as suas partes, para um aparecimento específico, "ditado" pelo sentido cadeira. E aqui está o grande momento! A cadeira, enquanto cadeira, é tão somente esse sentido que se abre para mais sentido. Ela é, em verdade, apenas a abertura, a passagem. Aqui, portanto, a coisa-cadeira deixa de ser coisa, e passa a ser sentido-cadeira, fenômeno-cadeira, aquilo que se abre e assim mostra - sempre mais e apenas - sentido.

Mas como esse sentido aparece? Por que a cadeira? Por que o sentido-cadeira? $\mathrm{Ou}$, ainda, por que e como cadeira é cadeira? Nosso nada não permite determinar o sentido, mas ser o seu lugar. Não fomos nós, na nossa indigência, que decidimos pela cadeira, nem ninguém decidiu, mas a cadeira já está decidida, e é com isso que devemos lidar: o sempre, o já, o decidido. Poderíamos inclusive levar a reflexão mais adiante, desviando-nos mais, aprofundando. Poderíamos nos perguntar: Por que nesta sala, junto com essas pessoas, numa exposição sobre Heidegger, sobre filosofia? Por que, afinal, estamos aqui? Ora, está decidido. Não temos como sair disso, estamos condenados. Nosso silêncio, se algum respeito tivermos por ele, por nós, nosso silêncio é o lugar da filosofia, é aqui que ela cresce, aparece.

O padre pediu silêncio para que escutássemos a voz do coração. Assim todos se calaram para que ele fosse ouvido, para que a sua voz pudesse nascer. A voz do coração pobre, mudo... De modo mais fundamental, a minha morte é lugar para tudo estar aqui, para tudo ser ouvido. Portanto, se há aqui filosofia, meu silêncio então deve simplesmente ser o seu onde: o próprio filosofar.

E, assim, voltando ao início desta conversa: talvez justamente nisso, no onde em que o sentido-filosofia atravessa, nasce, cresce, possamos encontrar Heidegger, sentado conosco, conversando em mesma disposição. Pois há dois tipos de conversa: aquela que mantemos com o padeiro e com o porteiro na lida cotidiana. Mas há uma conversa mais fundamental, uma conversa da alma, que é aquela que não se dá apenas no modo do dizer qualquer coisa, mas do fazer - ou, mais puramente, do deixar-ser. O padeiro não conversa conosco no seu fazer pão, pois não 


\section{Aoristo)))))}

International Journal of Phenomenology, Hermeneutics and Metaphysics

fazemos pão, mas ele conversa com outros padeiros justamente no mesmo fazer. É uma conversa essencial, na qual a língua, o idioma, é o padeirar. Também nós, mesmo não falando o alemão, mesmo sem nos termos com Heidegger, podemos conversar com ele, na medida em que nos abrimos para - ou, melhor, somos abertos no - filosofar. É aquela coisa da obediência, da escuta. Estamos decididos, é a nossa disposição, o sentido do nosso nada, o sentido que cresce, o meu sentido. Obediência: o meu deixar ser próprio, o meu me encontrar, ou, em palavras melhores, o meu aprender a morrer. Não somos donos da filosofia, não nos decidimos por ela, mas a deixamos se abrir em nosso silêncio, em nós mesmos. De novo, é a nossa disposição.

Mas como poderíamos fazer isso? Ou, melhor, como filosofia se faria em nós? Ora, desde o domingo em que, na fala do padre e no secreto da missa, estivemos eu e Jesus trocando olhares, não há lugar em que a resposta a essa questão não esteja posta. Nestas paredes, nas mesas, no texto, onde for, aí está o silêncio, aí está a minha morte, aí estou eu. E se a minha - ou, melhor, a nossa - afinação é realmente a filosofia, então nós somos o seu deixar-ser, de modo que basta, para ela, que guardemos a nossa ausência, que nos guardemos a nós mesmos. Façamos e, assim, sejamos silêncio - falando, conversando com Heidegger, escutando. Que cresça filosofia! Apenas isso.

Submetido: 11 de janeíro de 2021

Aceito: 10 de fevereiro de 2021 